УДК 340.151.

DOI 10.18413/2712-746X-2020-45-4-761-774

\title{
К вопросу о характере рецепции византийского права в средневековой Руси
}

\author{
Пенская Т.М., Тонков Е.Е., Туранин В.Ю. \\ Белгородский государственный национальный исследовательский университет, \\ Россия, 308015, г. Белгород, ул. Победы, 85 \\ E-mail: penskaya@bsu.edu.ru; etonkov@bsu.edu.ru; turanin@bsu.edu.ru
}

\begin{abstract}
Аннотация. На протяжении многих лет историки и правоведы, рассматривая процесс формирования правовой системы средневекового Русского государства, исходят из того, что серьезное влияние на него оказало византийское право - в первую очередь каноническое. Отсюда нередко делается вывод, что, поскольку византийское право генетически восходит к классическому римскому праву, то на Руси довольно рано познакомились с основами римского права и начали его усваивать в той или иной форме. Однако в последнее время эта традиционная и устоявшаяся точка зрения подвергается обоснованной критике. Используя новые подходы, авторы статьи предлагают рассмотреть проблему рецепции византийского права на Руси исходя из особенностей историко-культурного контекста этого процесса. Основываясь на результатах его анализа, авторы приходят к выводу о том, что русское общество эпохи раннего Средневековья не было готово к полноценной рецепции норм византийского права, которое воспринималось в русской интеллектуальной среде того времени как памятник христианской культуры, часть православной традиции, но не как юридический памятник и руководство к повседневной судебной деятельности.
\end{abstract}

Ключевые слова: Византия, Древняя Русь, римское право, каноническое право, Русская Правда, рецепция права.

Для цитирования: Пенская Т.М., Тонков Е.Е., Туранин В.Ю. 2020. К вопросу о характере рецепции византийского права в средневековой Руси. NOMOTHETIKA: Философия. Социология. Право. 45 (4): 761-774. DOI 10.18413/2712-746X-2020-45-4-761-774

\section{On the question of the nature of the reception of Byzantine law in medieval Russia}

\author{
Tatyana M. Penskaya, Evgeniy E. Tonkov, Vladislav Yu. Turanin \\ Belgorod National Research University, \\ 85 Pobeda St, Belgorod, 308015, Russia \\ E-mail: penskaya@bsu.edu.ru; etonkov@bsu.edu.ru; turanin@bsu.edu.ru
}

\begin{abstract}
For many years, historians and legal scholars have considered the process of forming the legal system of the medieval Russian state. They proceeded from the fact that Byzantine law, primarily canonical, had a serious impact on him. From this it is often concluded that, since Byzantine law genetically goes back to classical Roman law, in Russia they got acquainted with the basics of Roman law quite early and began to assimilate it in one form or another. Recently, however, this traditional and entrenched point of view has come under justified criticism. Using new approaches, the authors of the article propose to consider the problem of the reception of Byzantine law in Russia based on the peculiarities of the historical and cultural context of this process. Based on the results of his analysis, the authors come to the conclusion that the Russian society of the early Middle Ages was not ready for a fullfledged reception of the norms of Byzantine law. It was perceived by the Russian intellectual
\end{abstract}


environment of that time primarily as a monument of Christian culture, part of the Orthodox tradition, but not as a legal monument and a guide to everyday judicial activity

Keywords: Byzantium, Ancient Russia, Roman law, church law, Russian Truth, reception of law.

For citation: Penskaya T.M., Tonkov E.E., Turanin V.Yu. 2020. On the question of the nature of the reception of Byzantine law in medieval Russia. NOMOTHETIKA: Philosophy. Sociology. Law series. 45 (4): 761-774 (in Russian). DOI 10.18413/2712-746X-2020-45-4-761-774

С давних пор устоялось мнение не только в научном мире, но и в общественном мнении, что Византия стала своего рода «наставницей» Руси, ее «учительницей», и, как следствие, русская средневековая культура (в широком смысле) многое переняла от Византии. Естественно, что эта традиция не могла не затронуть и историю права - многие отечественные ученые посвятили свои изыскания поиску доказательств тезиса о существовании определенной преемственности между правом византийским и средневековым русским правом.

Определенная логика в этом, конечно же, есть. Трудно не согласиться с мнением, которое высказал один из крупнейших отечественных византинистов Г.Г. Литаврин, который в одной из своих работ писал о том, что «официальная государственная доктрина на Руси, как и в самой империи и других "православных" государствах юго-востока Европы и Кавказа, опиралась на учение восточнохристианской церкви... Неофиты не могли воспринять византийскую религиозную доктрину частично или в модифицированном виде. Они должны были усвоить ее целиком, вместе с учением о верховной государственной власти, которое содержалось в ней как ее неотьемлемый атрибут...» [Литаврин, 1999, c. 471]. И, само собой, вместе с этой доктриной на Руси должно было быть усвоено в той или иной форме и византийское право, на которое опиралась и из которого вытекала эта доктрина. А так как сами византийцы, по словам другого византиниста, Г.Л. Курбатова, «всегда считали себя «римлянами» - ромеями, а свое государство римским - ромейским» [Курбатов,1991. с. 15], то напрашивался вывод - на Руси должны были познакомиться и с основами права римского, которые являлись таковыми и для права византийского.

Веские основания полагать, что на Руси византийское право было известно, есть. Так, например, В.М. Живов отмечал, в частности, что «в России переписывались и распространялись памятники византийского законодательства в церковнославянском переводе», причем речь шла «не только о памятниках канонического права, но и о светских юридических памятниках, таких как - прежде всего - Эклога ("Леона царя премудраго и Константина верною царя главизны") и Прохирон ("Закон градский")». Кроме того, продолжал дальше исследователь свою мысль, «на Руси имели хождение отдельные выборки из кодификаций императора Юстиниана, входившие в своды византийского канонического права, переведенные на церковнославянский язык (Кормчие и Мерила Праведные), а также ряд других византийских юридических кодексов» [Живов, 2002a, с. 187-188]. Более того, тот факт, что на Руси наличествовали переводы византийских правовых норм на церковнославянский язык, был установлен еще в 1-й половине XIX в., фактически на заре становления русской истории права как отрасли юридической и исторической наук. Как писал еще в 1843 г. Н. Рождественский, «россияне, приняв христианскую веру от греков, заимствовали также от них законы. Греческие законы служили дополнением Русской Правды, Судебников; они служили дополнением и источником Уложения Алексея Михайловича. Даже по издании Уложения, не только духовные места и власти, но часто гражданские судебные места, в случае недостатка отечественных законов, прибегали к узаконениям греческим и решили по оным дела гражданские и уголовные» (правда, исто- 
рик отмечал, что греческие законы для русских служили «правом вспомогательным (jus subsidiarium)») [Рождественский, 1843, с. 5].

Это положение получило свое развитие в трудах последующих поколений русских историков и правоведов. Так, В.С. Иконников в конце 60-х гг. XIX в. отмечал, что «преобладание в течении продолжительного периода греческого элемента в высшей иерархии России (имеется в виду церковная иерархия - Aвm.), при слабости ее юридических форм, содействовало широкому применению византийских юридических источников к русскому законодательству, которое, начавшись в духовной сфере, благодаря смешению церковного элемента с светским, отличавшим византийскую юриспруденцию, перешло в область гражданскую и господствовало в течении всего древнего периода русской истории» [Иконников, 1869, с. 369].

М.Ф. Владимирский-Буданов в след за В.С. Иконниковым отмечал, что «в конце $\mathrm{X}$-го в. (988 г.) сношения с Византиею привели к принятию христианства, что произвело совершенный переворот во всех сферах правовой жизни», и хотя этот переворот и не привел к полному вытеснению старого обычного права новым, однако поспособствовал усвоению церковного (канонического) права и «К частичной и сводной рецепции некоторых кодексов византийского светского права» [Владимирский-Буданов, 1900, с. 99].

Другой классик русского правоведения, В.И Сергеевич [1903], также отмечал несомненное влияние византийского права на формирование и последующее развитие русского средневекового права, в особенности церковного, увязывая это влияние с крещением Руси. О том, что византийские своды церковного (канонического) и светского права использовались на Руси и выступали одним из источников при формировании собственно русского права, писал и М.А. Дьяконов [2005].

Традиция эта была продолжена и в советское время (естественно, с поправкой на господствующую идеологию и соответствующую ей методологию). Так, Я.Н. Щапов, характеризуя распространение переводных текстов с византийскими юридическими текстами, указывал на то, что «юридические произведения и компиляции, содержащие византийские правовые нормы, пользовались большим вниманием [на Руси], их не только читали и переписывали, но и перерабатывали, стремясь приблизить к условиям Руси» [Щапов, 1978, с. 10]. Проблемам рецепции византийского права в средневековой русской юридической традиции посвятил серию своих работ и Л.В. Милов [2009абв]. При этом исследователи, так или иначе касавшиеся этой проблемы, сходились, как правило, на том, что в первую очередь русскими «законниками» (можно ли их считать юристами или правоведами в современном смысле этих терминов - этот вопрос необходимо рассматривать отдельно), происходившими преимущественно из церковной среды, заимствовались нормы византийского церковного права, а уж затем - светского, причем в первую очередь в сфере регулирования брачно-семейных и наследственных отношений.

Нельзя сказать, чтобы положение существенно изменилось в постсоветское время. Традиция, заложенная в прежние десятилетия, продолжала воспроизводиться и в конце XX - начале XXI вв. [Еремян, 2000; Георгиевский, 2009; Гриднев, 2009; Бондаренко, 2010; Кравченко, 2014], и отдельные голоса [Новицкая, 2000; Томсинов, 2009], указывающие на необходимость пересмотра традиционного взгляда на рецепцию византийского права на Руси, общей картины не меняют.

Вместе с тем, указывая на существование определенной преемственности в развитии права византийского и права русского, обусловленной бытованием византийских юридических текстов в русской книжности эпохи Средневековья, историки-приверженцы традиционной точки зрения на характер рецепции византийского права на Руси, как правило, исходили из результатов сравнительного анализа византийских правовых норм, изложенных в разного рода юридических сборниках как церковного, так и светского права, с аналогичными нормами средневекового русского права. И эти результаты как будто поз- 
воляли говорить о заимствовании на Руси византийских правовых норм в той или иной степени, прямо или косвенно, в адаптированной под местные условия, форме. Но, как отмечали авторы вступительной статьи к сборнику работ Ю.Г. Алексеева (который, кстати, немало времени посвятил изучению особенностей генезиса и развития русского права эпохи Средневековья, касаясь в том числе и проблем, связанных с византийским влиянием на эти процессы), «обсуждение вопроса о влиянии, а тем более о переносе ("трансфере") и использовании правовых норм, невозможно без учета контекста» [Петров и др., 2020, с. 13].

Принимая эту поправку, мы исходим из того, что упомянутый в ней «контекст» надо понимать в самом широком смысле - не только в социополитическом или сугубо юридическом плане, но и в социокультурном и иных аспектах, полагая, что нормы права выступают, прежде всего, как явление культуры (опять же - культуры в широком смысле). При чем этот «контекст» необходимо рассматривать, по меньшей мере, с двух сторон, равно русской и византийской - что могли и что хотели передать русичам их учителя и наставники греки и что хотели и что получили в конечном итоге ученики (и насколько они были готовы воспринять то, что им предлагали).

Исходя из этого тезиса, рассмотрим сперва «контекст» с византийской, греческой стороны. Прежде всего, необходимо определиться с тем, что представляло из себя византийское право, равно светское и духовное, к исходу X века - т.е. к тому времени, когда Русь пришла к христианству. Можно ли считать византийское право того времени равноценным римскому (в его юстиниановом изводе)? На наш взгляд, на этот вопрос можно ответить одновременно и «да», и «нет». Да - потому, что связь между византийским правом эпохи Македонской династии и восточноримским правом эпохи Юстиниана несомненна, равно как и преемственность. Нет - потому, что византийское право конца $\mathrm{X}$ в. все же существенно отличалось от восточноримского права сер. VI в., и на то были серьезные причины.

Классическое римское право в основе своей имело полисное право, оно родилось и развивалось в характерной среде, и среда эта ушла в прошлое в эпоху «Темных веков» и кризиса Империи во времена иконоборчества и исламской экспансии. Вместе с ней ушла в прошлое и та среда, которая питала и давала силы классическому римскому праву. Оскудевшая людьми и мыслью Империя уже не могла поддерживать прежний высокий уровень культурного развития, в том числе и в сфере юриспруденции. Как отмечал И.П. Медведев, «в период "темных веков" право и законодательство разделили судьбы византийской культуры: после грандиозных кодификационных работ, осуществленных правоведами юстиниановской эпохи, после хорошо налаженной государственной системы юридического образования, которая имела место прежде, правовая жизнь империи в конце VII - первой половине IX в. выглядит как время упадка. В упадок приходит не только императорское правотворчество, но и юриспруденция» [Медведев, 1989, с. 216]. В известном смысле можно говорить об определенной «варваризации» прежнего римского права, и памятником этого его упрощения и «опрощения» может служить знаменитая Эклога императора Льва III Исавра, которая, по мнению многих отечественных историков и правоведов, оказала значительное влияние на развитие русского средневекового права.

К особенностям Эклоги, отличавшим еe от юстиниановой кодификации, И.П. Медведев относил «чрезмерную лапидарность и явную неполноту юридического материала; оригинальность и самостоятельность структуры памятника, вызванные отсутствием подходящего образца; простоту и лаконичность стиля и языка», которые, видимо, были обусловлены упавшим уровнем юриспруденции в «Темные века» [там же, с. 216]. И, касаясь особенностей Эклоги и примыкавшим к ней дополнениям (Земледельческий закон, Морской закон и др.), исследователь отмечал далее, что уклонения от юстиниановой кодификации, допущенные составителями Эклоги, обусловили стремление позднейших византийских правоведов вернуться к началам [там же, с. 224]. Это стремление в конечном итоге привело к «"эллинизации" Юстиниановых законов, т. е. их перевода в греческую языковую систему и окончательного упразднения всех остатков латинской юриди- 
ческой терминологии» в Македонскую эпоху, так что, продолжал И.П. Медведев, «речь фактически шла о замене латинского Юстинианового корпуса греческим корпусом законов, о создании "греческого Юстиниана", Василик, посредством эксцерптирования старого законодательства, изменяемого путем всякого рода интерполяций, сокращений и дополнений, в упразднении всех остатков латинской юридической терминологии, которой были испещрены использованные редакторами Василик сочинения антецессоров, и в ее замене греческими эквивалентами» [там же, с. 227-228]. Производным из Василик и Эклоги стал знаменитый Прохирон Льва VI, который также полагается многими отечественными исследователями одним из источников русского средневекового права.

Однако одной только «варваризацией» классического римского права и его последовательной «эллинизацией» дело не ограничилось. Создание «греческого Юстиниана» неизбежно вело к тому, что в той или иной степени должен был возродиться дух старого греческого права, его глубинные, родовые черты. Последние же, по мнению отечественного антиковеда И.Е. Сурикова, заключались в том, что исследователю, который рискнет заняться изучением греческого права, придется иметь дело с «правом несистематизированным, нерефлектированным, обладающим неразвитым категориальным аппаратом, к тому же с правом, синкретически связанным с религией и этикой, не отделенными в достаточной мере от них (выделено нами - Авт.)...» [Суриков, 2004, с. 15].

Мы отнюдь не случайно выдели эту часть цитаты из работы историка, ибо связь религии (в нашем случае - православия в его ортодоксальном византийском изводе, окончательно установившемся после победы иконопочитателей над иконоборцами) и права в Византийской империи несомненна. Более того, светское и каноническое, церковное право в Империи переплелись настолько прочно, что разъединить их чрезвычайно сложно. Это и немудрено, если принять во внимание те отношения между Церковью и Властью, что установились в Византии еще на ранних этапах ее истории. «Великая византийская мечта», сложившаяся в сознании византийских интеллектуалов, по словам протоиерея Иоанна Мейендорфа, «рисовала универсальное - охватывающее весь мир - христианское общество, административно управляемое императором и духовно руководимое Церковью (выделено нами - Авт.)...» [Мейендорф, 2001, с. 301]. Больше того, православие для византийцев было не просто религией - нет, оно было существенно большим, выступая в роли той самой скрепы, что объединяла византийцев в единое целое. «Пеструю этнографическую смесь населения в Византии связывала и скрепляла религия в форме Православия... Православие было... господствующей национальностью византийского государства», писал русский византинист Н.И. Соколов [2005, с. 8].

Естественно, что в таком обществе обе ветви права неизбежно должны были не просто сосуществовать, но и самым теснейшим образом взаимодействовать, оказывая влияние друг на друга - в строгом соответствии с принципом пресловутой «симфонии», сформулированным Юстинианом в знаменитой преамбуле к VI новелле - тем самым, который провозгласил, что «Всевышняя благость сообщила человечеству два величайших дара - священство и царство: то [первое] заботится об угождении Богу, а это [второе] - о прочих предметах человеческих. Оба же, проистекая из одного и того же источника, составляют украшение человеческой жизни. Поэтому нет важнейшей заботы для государей, как благоустроение священства, которое, со своей стороны, служит им молитвой о них Богу. Когда и церковь со всех сторон благоустроена, и государственное управление движется твердо и путем законов направляет жизнь народов к истинному благу, то возникает добрый и благотворный союз церкви и государства, столь вожделенный для человечества...» [Цит. по: Курганов, 1881, с. 24]. Больше того, классическое римское право в Византии, испытав на себе «христианскую прививку» и пройдя через процесс «воцерковления», существенно переменилось. И снова процитируем мнение Н.И. Соколова. Он отмечал, что, по мере трансформации Восточноримской империи в Византийскую, «старые 
романские формы (и, само собой, это не могло не коснуться и правовых форм - Aвт.) получили на Востоке новое содержание, были одухотворены началами церковного учения и законодательства, с привнесением и эллинистических идей, и в результате царствование Юстиниана обогатило византинизм новыми правовыми понятиями, с существенным ущербом для романизма (выделено нами - Авт.)...» [Соколов, 2003, с. 12].

Подведем предварительный итог. Старое доброе римское право, нашедшее свое совершенное выражение в юстиниановой кодификации, спустя пять столетий, к исходу Х в., испытав на себе воздействие сразу трех процессов - «варваризации» «эллинизации» и «воцерковления», существенно изменилось и внешне, и внутренне. Новое византийское право, сохранив определенную генетическую связь с римским, тем не менее, было вполне самостоятельным и в известном смысле самобытным, оригинальным. И это исправленное и отредактированное «воцерковленное» имперское право, существенно отдалившееся от своего прародителя, должны были перенять русичи.

Но прежде чем перейти к анализу «русского» аспекта «контекста», коснемся важного, на наш взгляд, момента, связанного с рецепцией византийского права на Руси, а именно: что готовы были передать неофитам греки и входило ли сюда это самое римское право в его «воцерковленном» византийском варианте? Здесь стоит вспомнить слова, которые были произнесены императором Феофилом в адрес аббасидского халифа: «Глупо отдавать свое добро и раскрывать перед другими народами знание сущего, коим гордится и за что чтим всеми ромейский род» [Продолжатель Феофана, 2009, с. 125]. Вне всякого сомнения, кодифицированное, структурированное, высокоразвитое право было частью этого самого «знания о сущем», которым так гордились византийцы и которое, по их мнению, отличало их как высококультурный, цивилизованный народ от окружающих Империю беззаконных варваров. Собственно говоря, и сама миссия рассматривалась греками преимущественно сугубо прагматически. «Главное достоинство христианизации, - отмечал отечественный исследователь С.А. Иванов, - с точки зрения византийца, это «замирение», т.е., христианизация должна была «ограничивать дикость неофитов и обуздывать их агрессию против Византии (выделено нами - Aвm.)...» [Иванов, 2003, с. 343].

И, наконец, остается еще одни вопрос - а кто выступал в роли «переносчика» византийских культурных ценностей на Русь? И здесь нельзя на вспомнить про любопытные наблюдения, которые сделал в свое время В.М. Живов. Характеризуя византийскую культуру, он отмечал ее гетерогенный характер, выделяя в ней два тесно переплетенных компонента - условно говоря, «гуманистический», ориентированный в большей степени на греко-римскую классическую традицию, и «аскетический», повернутый лицом к традиции христианской (даже больше того - раннехристианской, неиспорченной еще плодами синтеза двух начал - античного и христианского). Нацеленность последнего, по словам исследователя, на аскетический и экклезиологический опыт, ее определенное равнодушие к античному интеллектуальному наследию и имперской идее, равно как и акривистское восприятие церковных установлений [Живов, 2002б, с. 75], не оставляла места для римской правовой традиции - в лучшем случае речь могла идти лишь о передаче определенных текстов, содержащих избранные нормы канонического права и уж совершенно точно не чуждого «аскетам» римского классического права (пусть даже и в юстиниановой редакции). Между тем, как показал исследователь, именно представители «аскетической» традиции играли заглавную роль в процессе катехизации Руси на ранних ее этапах [Живов, 2002б] - этапах тем более важных, если принять во внимание, что именно тогда закладывались основы новой, христианской, русской культуры.

Как результат, процесс передачи византийской культурной традиции на Русь носил однобокий, продиктованный требованиями миссии и катехизации населения, характер, и римское право явно не попадало в список первостепенных текстов, которые надлежало спешно перевести на церковнославянский язык и снабдить ими неофитов. Одним словом, на пути сколько-нибудь полноценной рецепции римского права в его византийском изво- 
де на Руси стояли серьезные преграды, преодолеть которые было чрезвычайно сложно. Но стремились ли русские книжники и «юристы» преодолеть эту пропасть? Каким был «русский» «контекст» этой рецепции? И здесь все было не так просто, как может показаться на первый взгляд.

Прежде всего необходимо обратить внимание на коренное отличие Западной Европы (по крайней мере, большей ее части и романской в первую очередь) от Руси в вопросе рецепции римского права. Раннесредневековые государства Западной Европы возникли и развивались на территориях бывшей Западной Римской империи с многочисленным романизированным населением, с соответствующими традициями и практиками - в том числе и правовыми. На протяжении определенного времени в этих государствах римское право продолжало функционировать - бывшие римляне продолжали жить именно по нему, поскольку пришельцы пользовались своим собственным традиционным германским правом. Это сосуществование двух правовых систем и их постепенное взаимопроникновение облегчили рецепцию римского права в Западной Европе, тем более, что очень скоро латинский язык, язык церкви, занял прочные позиции и в государственном управлении, и в судопроизводстве, и в среде интеллектуалов, став настоящим lingua franca средневековой Европы.

Иначе развивались события на Руси. Культурный субстрат, на котором формировалось раннесредневековое Русское государство (именуемое традиционно Киевской Русью), был совершенно иным, нежели в Западной Европе, и представлял собой своего рода «целину», не затронутую римским (и тем более византийским) влиянием. В этом плане Русь более схожа со Скандинавией и раннесредневековой Англией - с той поправкой, что Русь оказалась после начала Великий Схизмы 1054 г. за пределами латинской Respublica Christiana. Соответственно, и почвы для рецепции римского права, подготовленной долгим сосуществованием двух правовых систем, не было.

Свою негативную роль сыграл также и языковой барьер (и связанный с ним барьер культурный). Если на Западе, как уже было отмечено выше, латинский язык стал lingua franca, то для «Византийского содружества наций» греческий язык не стал аналогом латыни и тем самым не сыграл той роли, которую сыграла латынь в жизни западноевропейского средневекового общества. Не зная в совершенстве греческого языка и не будучи погруженными в культурную жизнь Константинополя, русские книжники были вынуждены довольствоваться переводной литературой, в которой юридические тексты явно занимали не одно из первых мест. Положение могло бы быть исправлено, если бы на Русь в качестве церковных иерархов прибыли бы такие представители просвещенной византийской элиты, как Феофилакт Охридский, который, хотя и ощущал себя, пребывая на охридской кафедре, в духовной и интеллектуальной пустыне [Оболенский, 1998], тем не менее, исправно отправлял свои пастырские обязанности перед болгарами, которых он считал диким и грубым варварским народом. Однако на киевской кафедре в то время, когда закладывались основы русской книжной и интеллектуальной традиции, подобного человека не оказалось.

Определенные проблемы создавала и разность в уровне культурного развития между греками и русичами. Присущий просвещенным византийцам определенный культурный снобизм, корнями своими уходящий в античную традицию противопоставления эллинства и варварства, имел под собою веские основания. В VII-XII вв., вплоть до «интеллектуальной» революции на Западе, византийская цивилизация безусловно наголову превосходила западноевропейскую и русскую. Философия, общественно-политическая мысль, наука, образование, дипломатия, военное дело, образ жизни, церемониалы, искусство, право, государственное управление - какую не возьми область, везде византийцы задавали тон и чувствовали себя безусловными господами над темными и необразованными европейцами-варварами и точно такими же, с их точки зрения, варварами-русичами. В течение всего раннего и значительной части развитого Средневековья она выступала в 
качестве практически единственной хранительницы античного наследия, откуда исходили мощные культурные импульсы. Как результат, ничего равноценного русичи грекам противопоставить не могли, более того, и воспринять это богатство они также были не в состоянии - с одной стороны, потому как на Русь транслировалась лишь часть греческого культурного наследия, а с другой стороны - интеллектуальный уровень русских книжников еще не был настолько изощрен, чтобы разобраться во всех хитросплетениях греческой мысли (уже хотя бы потому, что на Руси, как было отмечено чуть выше, блестящих знатоков греческого языка было всегда немного).

Положение могло бы быть исправлено, если бы на Руси сложилась система образования, в чем-то схожая с византийской. Как отмечал французский византинист П. Лемерль, в Византии изначально «торжествующее христианство ... не привело к созданию христианской школы со своими внушениями и программами и к навязыванию ее вместо школы языческой». Как результат, продолжал он, «школьное и университетское образование остается таким, каким было, и христианство, принимая меры предосторожности, приспосабливается к нему» (выделено нами - Aвт.)...». И, характеризуя сущность процесса этого приспособления, далее Лемерль отмечал, что христианские апологеты времен поздней античности в конце концов «соглашаются, что свободные искусства, если и не являются самоцелью, представляют собой мастерство, которое нужно поставить на службу религии» и «признают практическую необходимость для детей посещать общественные школы, которые открывают путь к государственной карьере и повышению социального статуса [Лемерль, 2017, с. 65, 67].

Одним словом, есть все основания согласиться с мнением В.М. Живова, который по этому поводу писал, что в сфере образования в Византии «преемственность по отношению к античной культуре все же сохранялась, несмотря на религиозное противостояние и новый культурный контекст» и «те изменения, которые происходили позднее (в частности, упадок интереса к классическому наследию в VIII в. а актуализация этого интереса в IX-XI вв.), принципиального влияния на тип культуры (отличающей Византию от древней Руси или Западной Европы в раннее средневековье) не оказывали» [Живов, 2002б, с. 81]. Правда, стоит отметить, что «традиционное» образование в Византии носило все же ярко выраженный элитарный характер и концентрировалось в немногих городах (прежде в столице) - на это обстоятельство указывали, к примеру, П. Лемерль [2017, с. 376] и Д. Оболенский [1998, с. 444]. Из этого следует, что это «знание о сущем», оставаясь достоянием чрезвычайно узкой группы византийских интеллектуалов, за рамки этого практически и не выходило и попасть на Русь не могло - за отсутствием носителей.

Но тогда возникает вопрос: а какой характер носило образование на Руси? В.М. Живов по этому поводу писал, что «на Руси образование носило исключительно катехитический характер: образованность не вырастает здесь, как в Византии, из античной традиции, а поначалу целиком связана с миссией» [Живов, 2002б, с. 83]. Катехитический характер образования накладывал свои условия и на состав раннесредневековых русских библиотек, структура которых определялась требованиями богослужебной традиции. Как отмечал А.М. Пентковский, «Устав (Типикон) являлся основным регулятором церковнобогослужебной практики, а также существенно влиял на строй религиозной и бытовой жизни средневекового общества (выделено нами - Aвm.)...». И продолжа свою мысль дальше, исследователь указывал на следующее важное для нашего небольшого исследования обстоятельство: «Регламентируя богослужебную практику, Устав (Типикон) определял набор и состав богослужебных и четьих книг - основной составляющей книжного комплекса Древней Руси (выделено нами - Авm.)...» [Круглый стол..., 1988, с. 3940]. Первоначальный базовый состав русской книжности определял т.н. Типикон Великой Церкви [См., например: Лисицын, 1911, с. 160], и рукописи, которые входили в него, не включали в себя правовые тексты. Не отличался от него в этом отношении и пришедший 
на Русь несколько позднее Студийско-Алексиевский Устав [См.: Круглый стол..., 1988, с. 39-41; Горский, Невоструев, 1869, с. 239].

Как результат, аскетическая традиция прочно утвердилась на Руси и оказалась настолько устойчивой, что, как отмечал В.М. Живов, «при любых послаблениях государственной религиозной и культурной политики ... вновь являет свою жизненность, пробиваясь как зелень через потрескавшийся камень» даже спустя столетия после возникновения [Круглый стол..., 1988, с. 38]. Стоит ли после этого удивляться тому, что в сер. XII в. митрополит всея Руси Климент Смолятич оправдывается перед смоленским пресвитером Фомой за то, что в переписке с князем «оставль аз почитаема Писаниа, аз писал от Омира, и от Аристотеля, и от Платона, иже во елиньскых нырех славнее быша» [Послание..., 1997, с. 118], а двумя столетиями позже тверской инок Фома поучал в первой половине XIV в. своих читателей, что ответы на интересующие их вопросы нужно искать прежде всего в Священном Писании: «Аще ли хощеши почести душеспасительные книги, и тъ почти святых отец житиа их; и аще ли хощеши посланий чести, то апостольскыи книги имаши; и аще ли хощеши повестных книг, то почти Царства...» [Инока Фомы..., 1908, с. 27]. Больше того, наставляя своих учеников в истинной вере, еще спустя два столетия знаменитый расколоучитель протопоп Аввакум поучал их: «Не ищите риторики и философии, ни красноречия, но здравым истинным глаголом последующе, поживите. Понеже ритор и философ не может быть християнин (выделено нами - Aвm.)...». О себе же Аввакум писал, что «аз есмь ни ритор, ни философ, дидаскалства и логофетства неискусен, простец человек и зело исполнен неведения» [Житие..., 1979, с. 120].

Утвердившаяся на Руси на заре ее христианизации византийская аскетическая культурная традиция неизбежно привела к тому, что русская книжность, по словам итальянского русиста Р. Пиккио, «усвоила только одну фазу ее (византийской культурной традиции - прим. Авт.) развития, как бы оторвав современную для себя Византию от ствола античности». И русские интеллектуалы, продолжал он, обращались к греческой традиции, «не за какими-то определенными техническими знаниями, знаниями практическими, но для того, чтобы овладеть мудростью в абсолютном смысле, то есть Истиной, которую дает не человеческая ученость, а божественное Откровение (выделено нами - Aвт.)...» [Пиккио, 2002, с. 41]. Согласимся с тем, что право, неважно, римское ли или византийское «воцерковленное», имело отношение к этой Истине и этому Откровению опосредованное, подчиненное и уж никак не определяющее и самоценное, заслуживающее изучения, комментирования, цитирования и тем более постоянного практического использования.

Подводя промежуточный итог, отметим, что культурно-исторический субстрат, тот самый «контекст», о котором шла речь прежде, явно неблагоприятствовал рецепции римского права (в его византийском изводе) на Руси. Русское общество не было готово к этому ни в политическом, ни в социальном, ни в культурном отношении. Однако бытование на Руси норм византийского права, светского (хотя, впрочем, как уже было отмечено выше, светское и каноническое право в Византии были тесно связаны друг с другом) и в особенности канонического, не вызывает сомнения. Так, М.Ф. Владимирский-Буданов отмечал, что светское византийское право попало на Русь в составе сборников византийского же канонического права (номоканонов и кормчих). Он писал, что «в Русской Правде есть весьма близкие заимствования из светских памятников кормчей», причем «возможность заимствования облегчалась тем, что византийские кодексы (особенно иконоборческой эпохи) составлены под явным влиянием славянского элемента в самой Византии». При этом, продолжал он развивать свою мысль, заимствования эти осуществлялись не догматично, слово в слово, а с определенной свободой [Владимирский-Буданов, 1900, с. 100].

С каноническим правом ситуация выглядит как будто несколько проще уже хотя бы потому, что для урегулирования возникающих в повседневной жизни «общины вер- 
ных» отношений нормы канонического права были необходимы (впрочем, и здесь остается вопрос - насколько реально они применялись на практике, учитывая проблемный уровень христианизации основной массы прихожан и невысокий образовательный уровень большей части священников). С нормами светского права положение было иным. Британский историк С. Франклин выдвинул любопытный тезис, согласно которому неразвитость официальной письменности, которая бы активно использовалась органами княжеской власти, объясняется не тем, что сам по себе государственный аппарат был неразвит и примитивен (хотя, безусловно, сравнивая его с византийской бюрократической машиной, такой вывод сделать можно легко и непринужденно). Этот факт, по мнению историка, «указывает на устойчивость традиционных социальных отношений, на осознанную обществом функциональную адекватность традиционных способов поведения без участия письменности, на самодостаточность традиции (выделено нами - Aвm.)...» [Франклин, 2010, c. 476].

Представляется, что именно эта сохранявшаяся на протяжении долгого времени адекватность традиционных способов урегулирования возникающих внутри общества проблем создавала серьезные препятствия, которые вкупе с отмеченными выше обстоятельствами формирования соответствующего «контекста» рецепции создавали серьезные же проблемы на пути полноценного восприятия норм византийского права на Руси. И когда К.В. Петров, касаясь проблем рецепции византийского права на Руси, писал о том, что «византийские правовые тексты, с одной стороны, в большей мере носили характер определенного эталона, образца, к которому нужно было бы стремиться (выделено нами - Авт.)...» [Петров, 2013, с. 42], то, пожалуй, с этим наблюдением стоит согласиться, причем его можно перенести не только на светское, но и в известной степени - на каноническое право. К схожему по духу выводу приходит и В.М. Живов, который отмечал, что «функции византийско-церковнославянских юридических памятников относятся к ... сфере идеологии; эти памятники воспринимаются как часть христианской культуры и получают религиозную, а не практическую значимость (выделено нами - Aвm.)...» [Живов, 2002в, с. 297]. Отношение к византийскому праву в любой его редакции как к памятнику христианской культуры, как к части «знания о сущем», того самого Откровения и Истины, в таком случае позволяет дать ответ на вопрос - почему на Руси не сложилась традиции оживленного переписывания, комментирования и разработки юридических текстов (равно канонических и светских, своих и византийских) и почему юридические памятники, как правило, сохраняются в составе сборников компилятивного содержания. И сама по себе рецепция норм византийского права на Руси носила весьма ограниченный характер. В лучшем случае нормы византийского права выступали в роли «субсидиарного» права, помогая разрешить спорную ситуацию, которая не могла быть удовлетворительно разрешена в рамках обычного права (однако и в этом случае нужно исходить из того, насколько доступны были рукописи, содержащие византийские правовые тексты, тем, от кого зависело принятие конкретных решений).

\section{Список источников}

1. Владимирский-Буданов М.Ф. 1900. Обзор истории русского права. СПб.-Киев, Изд.-е книгопродавца Н.Я Оглоблина, 667 с.

2. Горский А.В., Невоструев К.И. 1869. Описание славянских рукописей Московской Синодальной библиотеки. Отд. 3. Книги богослужебные, Ч. 1. М., Синод. Тип-я, 584 с.

3. Житие протопопа Аввакума, им самим написанное, и другие его сочинения. 1979. Иркутск, Восточно-Сибирское книжное издательство, 367 с.

4. Иконников В.С. 1869. Опыт изследования о культурном значении Византии в русской истории. Киев, Университетская типография, $572 \mathrm{c.}$

5. Инока Фомы слово похвальное о благоверном великом князе Борисе Александровиче. 1908. Памятники древней письменности и искусства. T. CLXVIII: $1-55$.

6. Круглый стол: 1000-летие Крещения Руси. 1988. Советское славяноведение, 6: 10-75. 
7. Курганов Ф.А. 1881. Византийский идеал царя и царства и вытекающие отсюда, по сравнению с идеалом церкви, отношения между церковной и гражданской властью. Казань: Тип. Имп. ун-та, 36 с.

8. Лисицын М. 1911. Первоначальный славяно-русский Типикон. Историкоархеологическое исследование. СПб., тип. В.Д. Смирнова, 386 с.

9. Послание, написано Климентом, митрополитом рускым, Фомъ, прозвитеру смоленскому, истолковано Афонасиемь мнихомъ. 1997. В кн.: Библиотека литературы Древней Руси. Т. 4. СПб., Наука, 118-141.

10. Продолжатель Феофана. 2009. Жизнеописания византийский царей. Изд. подгот. Я.Н. Любарский. СПб., Алетейя, 400 с. (ЛП)

11. Рождественский Н. 1843. Разсуждение о влиянии греко-римского права на российские гражданские законы. СПб., Тип. Штаба военно-учебных заведений, 158 с.

Сергеевич В.И. 1903. Лекции и изследования по истории древнего русского права. СПб., Тип. М.М. Стасюлевича, 664 с.

\section{Список литературы}

1. Бондаренко Ю.В. 2010. К проблеме рецепции византийского права в древнерусском законодательстве. Пробелы в российском законодательстве, 4: 274-276.

2. Георгиевский Е.В. 2009. К вопросу об общей характеристике и происхождении Русской Правды. Сибирский юридический вестник. 1 (44): 74-81.

3. Гриднев А.Н. 2009. Роль византийского права в формировании древнерусской государственности. Пробелы в российском законодательстве, 3: 207-209.

4. Дьяконов М.А. 2005. Очерки общественного и государственного строя Древней Руси. СПб., Наука, 384 с.

5. Еремян Э.В. 2000. Древнеславянская Кормчая на Руси как часть византийского правового наследия. Вестник РУДН. Серия Юридические науки, 1: 197-199.

6. Живов В.М. 2002а. Postscriptum. В кн.: Живов В.М. Разыскания в области истории и предыстории русской культуры. М., Языки славянской культуры, 291-305.

7. Живов В.М. 2002б. История русского права как лингвосемиотическая проблема. В кн.: Разыскания в области истории и предыстории русской культуры. М.: Языки славянской культуры: 187-290.

8. Живов В.М. 2002в.Особенности рецепции византийской культуры в древней Руси. В кн.: Разыскания в области истории и предыстории русской культуры. М., Языки славянской культуры: 73-115.

9. Иванов С.А. 2003. Византийское миссионерство: Можно ли сделать из «варвара» христианина? М., Языки славянской культуры, 376 с.

10. Кравченко Е.В. 2014. Влияние византийских правовых норм на юридические памятники Древней Руси. Философия права, 5 (66): 120-124.

11. Курбатов Г.Л. 1991. Ранневизантийские портреты. К истории общественнополитической мысли. Ленинград, Изд-во ЛГУ: 270 с.

12. Лемерль П. 2017. Первый византийский гуманизм. Замечания и заметки об образовании и культуре в Византии от начала до X века. СПб., Свое издательство: XIV +490 с.

13. Литаврин Г.Г. 1999. Идея верховной государственной власти в Византии и Древней Руси домонгольского периода. В кн.: Литаврин Г.Г. Византия и славяне. СПб., Алетейя, 608 с.

14. Мейендорф И., прот. 2001. Византийское богословие. Минск, Лучи Софии, 336 с.

15. Медведев И.П. 1989. Развитие правовой науки. Культура Византии. Вторая половина VII-XII в. М., Наука, 216-240.

16. Милов Л.В. 2009а. Византийская Эклога и «Правда Ярослава» (к рецепции византийского права на Руси). В кн.: Милов Л.В. Исследования по истории памятников средневекового права. М., РОССПЭН, 173-186.

17. Милов Л.В. 2009б. Византийская Эклога и Пространная Русская Правда (проблемы рецепции). В кн.: Милов Л.В. Исследования по истории памятников средневекового права. М., РОССПЭН, 162-172.

18. Милов Л.В. 2009в. Проблемы рецепции византийского права в Древней Руси. В кн.: Милов Л.В. Исследования по истории памятников средневекового права. М., РОССПЭН, 314-327. 
19. Новицкая Т.Е. 2000. К вопросу о так называемой рецепции римского права в России. Вестник Моск. ун-та. Сер.11. Право, 3: 121-134.

20. Оболенский Д. 1998. Шесть византийских портретов. В кн.: Оболенский Д. Византийское содружество наций. Шесть византийских портретов. М., Янус-К, 655 с.

21. Петров К.В. 2013. К вопросу о рецепции византийского права на Руси. Русь, Россия: Средневековье и Новое время, 3: 38-43.

22. Петров К.В., Стрельников С.В., Штыков Н.В. 2020. Псков и Новгород в научном творчестве Ю.Г. Алексеева. В кн.: Алексеев Ю.Г. Псков и Новгород накануне присоединения к Российскому государству. СПб., Изд-во Олега Абышко: 5-20.

23. Пиккио Р. 2002. Древнерусская литература. М., Языки славянской культуры, 352 с.

24. Соколов И.И. 2003. О византинизме в церковно-историческом отношении. Избрание патриархов в Византии с середины IX до начала XV века (843-1453 г.). Вселенские судьи в Византии. СПБ., Изд-во Олега Абышко, 272 с.

25. Соколов Н.И. 2005. Лекции по истории Греко-Восточной церкви. Т. І. СПб., Изд-во Олега Абышко, 384 с.

26. Суриков И.Е. 2004. Проблемы раннего афинского законодательства. М., Языки славянской культуры, 144 с.

27. Томсинов В.А. 2009. Юриспруденция Древней Руси и правовая культура Византии. Вестник Московского университета. Сер. 11. Право, 4: 3-26.

28. Франклин С. 2010. Письменность, общество и культура в Древней Руси. СПб., Дмитрий Буланин, 552 с.

29. Щапов Я.Н. 1978. Византийское и южнославянское правовое наследие на Руси в XIХІІІ вв. М., Наука, 291 с.

\section{References}

1. Bondarenko Yu.V. 2010. K probleme recepcii vizantijskogo prava $\mathrm{v}$ drevnerusskom zakonodatel'stve [On the problem of the reception of Byzantine law in ancient Russian legislation]. Probely v rossijskom zakonodatel'stve, 4: 274-276.

2. Georgievskij E.V. 2009. K voprosu ob obshchej harakteristike i proiskhozhdenii Russkoj Pravdy [On the question of the general characteristics and origin of the Russian Truth]. Sibirskij yuridicheskij vestnik, 1 (44): 74-81.

3. Gridnev A.N. 2009. Rol' vizantijskogo prava v formirovanii drevnerusskoj gosudarstvennosti [The role of Byzantine law in the formation of ancient Russian statehood]. Probely $\mathrm{v}$ rossijskom zakonodatel'stve, 3: 207-209.

4. D'yakonov M.A. 2005. Ocherki obshchestvennogo i gosudarstvennogo stroya Drevnej Rusi [Essays on the social and state structure of Ancient Rus]. SPb., Publ.: Nauka, 384 p.

5. Eremyan E.V. 2000. Drevneslavyanskaya Kormchaya na Rusi kak chast' vizantijskogo pravovogo naslediya [Old Slavic Helmsman in Russia as part of the Byzantine legal heritage]. Vestnik RUDN. Seriya YUridicheskie nauki, 1: 197-199.

6. Zhivov V.M. 2002a. Istoriya russkogo prava kak lingvosemioticheskaya problema [History of Russian law as a semiotic linguistic problem]. In: Zhivov V.M. Razyskaniya v oblasti istorii i predystorii russkoj kul'tury [Research in the field of history and prehistory of Russian culture]. M., Publ.: Yazyki slavyanskoj kul'tury: 187-290.

7. Zhivov V.M. 2002b.Osobennosti recepcii vizantijskoj kul'tury v drevnej Rusi [Features of the reception of Byzantine culture in ancient Russia]. In: ZHivov V.M. Razyskaniya v oblasti istorii i predystorii russkoj kul'tury [Research in the field of history and prehistory of Russian culture]. M., Publ.: YAzyki slavyanskoj kul'tury: 73-115.

8. Zhivov V.M. Postscriptum. 2002v. In: Zhivov V.M. Razyskaniya v oblasti istorii i predystorii russkoj kul'tury [Research in the field of history and prehistory of Russian culture]. M., Publ.: Yazyki slavyanskoj kul'tury, 291-305.

9. Ivanov S.A. 2003. Vizantijskoe missionerstvo: Mozhno li sdelat' iz «varvara» hristianina? [Byzantine Missionary: Can You Make a Christian Out of a "Barbarian"?]. M., Publ.: Yazyki slavyanskoj kul'tury, $376 \mathrm{p}$. 
10. Kravchenko E.V. 2014. Vliyanie vizantijskih pravovyh norm na yuridicheskie pamyatniki Drevnej Rusi [Kravchenko E.V. The influence of Byzantine legal norms on the legal monuments of Ancient Rus]. Filosofiya prava, 5 (66): 120-124.

11.Kurbatov G.L. 1991. Rannevizantijskie portrety. K istorii obshchestvenno-politicheskoj mysli [Early Byzantine portraits. To the history of social and political thought]. Leningrad, Publ.: LGU, 270 p.

12. Lemerl' P. Pervyj vizantijskij gumanizm. 2017. Zamechaniya i zametki ob obrazovanii i kul'ture v Vizantii ot nachala do X veka [The first Byzantine humanism. Observations and notes on education and culture in Byzantium from the beginning to the 10th century]. SPb., Publ.: Svoe izdatel'stvo: XIV +, $490 \mathrm{p}$.

13. Litavrin G.G. 1999. Ideya verhovnoj gosudarstvennoj vlasti v Vizantii i Drevnej Rusi domongol'skogo perioda [The idea of the supreme state power in Byzantium and Ancient Russia of the pre-Mongol period]. In: Litavrin G.G. Vizantiya i slavyane [Byzantium and the Slavs]. SPb. Publ.: Aletejya, $608 \mathrm{p}$. Sofii, $336 \mathrm{p}$.

14. Mejendorf I., prot. 2001. Vizantijskoe bogoslovie [Byzantine theology]. Minsk, Publ.: Luchi

15. Medvedev I.P. 1989.Razvitie pravovoj nauki [Development of legal science]. Kul'tura Vizantii. Vtoraya polovina VII-XII v. [Culture Of Byzantium. Second half of VII-XII centuries.]. M., Publ.: Nauka, 216-240.

16. Milov L.V. 2009a. Problemy recepcii vizantijskogo prava v Drevnej Rusi [Problems of the reception of Byzantine law in Ancient Russia]. In: Milov L.V. Issledovaniya po istorii pamyatnikov srednevekovogo prava [Research on the history of monuments of medieval law]. M., Publ.: ROSSPEN, 314-327.

17. Milov L.V. 2009b. Vizantijskaya Ekloga i «Pravda YAroslava» (k recepcii vizantijskogo prava na Rusi) [Byzantine Eclogue and "Yaroslav's Truth" (to the reception of Byzantine law in Russia)]. In: Milov L.V. Issledovaniya po istorii pamyatnikov srednevekovogo prava [Research on the history of monuments of medieval law]. M., Publ.: ROSSPEN, 173-186.

18. Milov L.V. 2009v. Vizantijskaya Ekloga i Prostrannaya Russkaya Pravda (problemy recepcii) [Byzantine Eclogue and Extensive Russian Truth (problems of reception)]. In: Milov L.V. Issledovaniya po istorii pamyatnikov srednevekovogo prava [Research on the history of monuments of medieval law]. M., Publ.: ROSSPEN, 162-172.

19. Novickaya T.E. 2000. K voprosu o tak nazyvaemoj recepcii rimskogo prava v Rossii [On the question of the so-called reception of Roman law in Russia]. Vestnik Mosk. Un-ta, Ser.11. Pravo. 3: 121134.

20. Obolenskij D. 1998. Shest' vizantijskih portretov [Six Byzantine portraits]. In: Obolenskij D. Vizantijskoe sodruzhestvo nacij. SHest' vizantijskih portretov [The Byzantine Commonwealth of Nations. Six Byzantine portraits]. M., Publ.: YAnus-K, 655 p.

21. Petrov K.V. 2013. K voprosu o recepcii vizantijskogo prava na Rusi [On the question of the reception of Byzantine law in Russia]. Rus', Rossiya: Srednevekov'e i Novoe vremya, 3: 38-43.

22. Petrov K.V., Strel'nikov S.V., Shtykov N.V. 2020. Pskov i Novgorod v nauchnom tvorchestve Yu.G. Alekseeva [Pskov and Novgorod in the scientific work of Yu.G. Alekseeva]. In: Alekseev YU.G. Pskov i Novgorod nakanune prisoedineniya k Rossijskomu gosudarstvu [Pskov and Novgorod on the eve of joining the Russian state]. SPb., Publ. Olega Abyshko, 5-20.

23. Pikkio R. 2002. Drevnerusskaya literatura [Old Russian literature]. M., Publ.: Yazyki slavyanskoj kul'tury, $352 \mathrm{p}$.

24. Sokolov I.I. 2003. O vizantinizme v cerkovno-istoricheskom otnoshenii. Izbranie patriarhov v Vizantii s serediny IX do nachala XV veka (843-1453 g.). Vselenskie sud'i v Vizantii [On Byzantinism in Church History. Election of patriarchs in Byzantium from the middle of the 9th to the beginning of the 15th century (843-1453). Ecumenical judges in Byzantium]. SPB., Publ. Olega Abyshko, 272 p.

25. Sokolov N.I. 2005. Lekcii po istorii Greko-Vostochnoj cerkvi [Lectures on the history of the Greek-Eastern Church]. Vol. I. SPb., Publ. Olega Abyshko, 384 p.

26. Surikov I.E. 2004. Problemy rannego afinskogo zakonodatel'stva [Problems of early Athenian legislation]. M., Publ.: Yazyki slavyanskoj kul'tury, 144 p.

27. Tomsinov V.A. 2009. YUrisprudenciya Drevnej Rusi i pravovaya kul'tura Vizantii [The jurisprudence of Ancient Rus and the legal culture of Byzantium]. Vestnik Moskovskogo universiteta. Ser. 11. Pravo, 4: 3-26. 
28. Franklin S. 2010. Pis'mennost', obshchestvo i kul'tura v Drevnej Rusi [Writing, society and culture in Ancient Russia]. SPb., Publ.: Dmitrij Bulanin, 552 p.

29. Shchapov YA.N. 1978. Vizantijskoe i yuzhnoslavyanskoe pravovoe nasledie na Rusi v XI XIII vv. [Byzantine and South Slavic legal heritage in Russia in the XI-XIII centuries]. M., Publ.: Nauka, $291 \mathrm{p}$.

\section{ИНФОРМАЦИЯ ОБ АВТОРАХ}

Тонков Евгений Евгеньевич, директор юридического института НИУ «БелГУ», доктор юридических наук, профессор, заслуженный юрист Российской Федерации, г. Белгород, Россия

Пенская Татьяна Михайловна, доцент кафедры теории и истории государства и права юридического института НИУ «БелГУ», кандидат исторических наук, доцент, г. Белгород, Россия

Туранин Владислав Юрьевич, заведующий кафедрой теории и истории государства и права юридического института НИУ «БелГУ», доктор юридических наук, доцент, г. Белгород, Россия

\section{INFORMATION ABOUT THE AUTHORS}

Evgeniy E. Tonkov, Director of the law Institute of the National Research University "BelSU", doctor of law, Professor, honored lawyer of the Russian Federation, Belgorod, Russia

Tatyana M. Penskaya, associate Professor of the Department of theory and history of state and law of the law Institute of the National Research University "BelSU", candidate of historical Sciences, associate Professor, Belgorod, Russia

Vladislav Yu. Turanin, head of the Department of theory and history of state and law of the law Institute of the National Research University "BelSU", doctor of law, associate Professor, Belgorod, Russi 